\title{
Economic benefit of back titration in the treatment of hypertension in Jos, Nigeria
}

\author{
Basil N Okeahialam' \\ Michael A Adeniyi² \\ 'Department of Medicine, Faculty \\ of Medical Sciences, ${ }^{2}$ Department of \\ Pharmaceutics and Pharmaceutical \\ Technology, Faculty of Pharmaceutical \\ Sciences, University of Jos, Jos, Nigeria
}

Correspondence: Basil N Okeahialam Department of Medicine, Faculty of Medical Sciences, Jos University Teaching Hospital, PMB 2078 Jos, Plateau State, Nigeria

$\mathrm{Tel}+2348051499271$

Email okeahbas@unijos.edu.ng
This article was published in the following Dove Press journal:

ClinicoEconomics and Outcomes Research

10 April 2017

Number of times this article has been viewed

Purpose: Treatment of hypertension is expensive and cost is one of the reasons for inadequate blood pressure control. Where there are no social cost cushions, the burden is borne by patients. With pervasive poverty and inadequate control, complications are unchecked. Back titration in appropriate circumstances should, therefore, translate to economic benefit. This is an attempt to compute, in economic terms, the benefit of back titration.

Patients and methods: Thirty-nine patients who entered an antihypertensive back titration program for 12 months and who had been earlier reported on, form the subject of this study. A survey of the cost of antihypertensives in pharmacy outlets in Jos, Nigeria was undertaken. Regimens of antihypertensives that patients were on at the onset and end of the 12 months of back titration were costed in Nigerian currency and compared.

Results: Back titration translated to economic benefit in all patients with a cost reduction varying from $2.3 \%$ to $100 \%$. This reflected in reduction in mean daily cost of treatment of N107.09-N54.61. Conclusion: The benefit of antihypertensive back titration apart from psychological relief of lower pill burden and side effect profile is in pharmacoeconomics. This permits greater adherence and prevents morbi-mortality consequences of hypertension. In this study, back titration over 12 months translated to average cost reduction of $>50 \%$, making treatment more affordable. In appropriate circumstances, back titration of antihypertensives results in economic relief for patients. This should improve adherence, reduce morbi-mortality and is recommended for wider application.

Keywords: hypertension, treatment, back titration, pharmacoeconomics, Nigeria

\section{Introduction}

What has been called epidemic of noncompliance has reached alarming proportions with $\sim 75 \%$ of Americans admitting to it. ${ }^{1}$ This has created unacceptable populationwide consequences in patients with chronic noncommunicable diseases, such as hypertension; ${ }^{2}$ where a reasonable proportion of medication related to hospital admission results from poor compliance, with an economic burden of close to $\$ 100$ billion annually. ${ }^{3}$ One of the reasons for patients' nonperseverance on drugs prescribed for hypertension is cost. ${ }^{4}$ This is commonplace in our environment; resource restricted settings where health expenses are usually out-of-pocket and largely unaffordable.

In a previous report by Okeahialam, ${ }^{5}$ the possibility of back titrating doses of antihypertensives after 12 months of consistent control was shown. In many, it was possible to still remain controlled with some de-escalation, and in a few cases to total discontinuation under continuing specialist care. One of the benefits canvassed in that report was psychological relief of lower pill burden and improvement in disease pharmacoeconomics. 
This work, therefore, was an attempt to put figures to pharmacoeconomic benefits of such management approach; which has been stressed should only be undertaken under continuing specialist care. In general, conventional economic studies in well-controlled clinical trials have not as yet assessed factors such as noncompliance, switching or treatment discontinuation which impact cost of therapy in hypertension. ${ }^{6}$

\section{Methods}

The 39 hypertension patients reported in the work referred to above by Okeahialam ${ }^{5}$ form the subject of this work. This was a subpopulation of hypertensives attending a specialist Hypertension Service who had no heart failure, kidney failure, recent ( $<6$ months) stroke or myocardial infarction; and had been controlled consistently for $\geq 12$ months. The principles of back titration were explained fully to them and they consented verbally to having their treatment de-escalated. They were followed up closely for 12 months; the ethics committee of Jos University Teaching Hospital granted approval of the study accordingly. The result of an audit after the 12 months of back titration has been published. ${ }^{5}$ Briefly following ascertainment of consistent control for $\geq 12$ months from the records, antihypertensive therapy in those consenting were sequentially back titrated starting with those on more than one drug. For those on monotherapy, dose was halved or interval of intake increased. Follow-up went on as usual for 12 months and back titration continued if blood pressure remained normal or reverted if blood pressure control was lost. This study is a secondary data analysis attempting to quantify monetary terms, the savings occasioned by the back titration. Using the reference retail price of antihypertensives as at November 2014 prepared by Michael A Adeniyi from a pharmacy retail outlet where he owns majority equity, we determined the cost of drugs at the onset and at the lowest levels maintaining control. Where a drug formulation had different generics, we used the brand with the highest cost for the cost computation. Though this is not the only pharmacy outlet that patients use for drug refill, the retail price of drugs in pharmacist-run outlets in Jos are generally uniform; 10\%-15\% mark-up over delivery prize by drug manufacturers and major distributors. We opted to use this instead of outlets run by dispensers with no formal pharmacy education because the in these, fake and substandard drugs that come incredibly cheaper could be found and efficacy becomes an issue. Any cost difference from beginning to end of observation period was calculated and difference/ cost at onset was computed as percentage difference. This study specifically looked at direct financial cost of drugs (paid out-of-pocket), as the patients experienced no other form of resource utilization like hospitalization. The facility was based purely on outpatient service; and no cost of specialist care was considered.

\section{Results}

The 39 patients included 14 males and 25 females, with ages ranging from 40 to 91 years. The saving on back titration varied depending on cost of $\operatorname{drug}(\mathrm{s})$ and quantum of reduction. It varied from 1 naira, 78 kobo (N1.78) to 212 naira, 25 kobo (N212.25) daily with percentage differences of $2.3 \%-100 \%$ (Table 1). This translates to heavy economic relief for people who, for lack of an effective health welfare scheme, bear the financial brunt of their treatment.

Table I Cost benefit of back titration in study subjects

\begin{tabular}{|c|c|c|c|c|}
\hline S. No. & Cost I (N) & Cost $2(\mathrm{~N})$ & Difference $(\mathbf{N})$ & Difference (\%) \\
\hline 1 & 68 & 2.25 & 65.75 & 98.5 \\
\hline 2 & 21.50 & 5.82 & 15.68 & 72.9 \\
\hline 3 & 25 & 3.57 & 21.43 & 85.7 \\
\hline 4 & 179 & 170 & 9 & 5 \\
\hline 5 & 152.50 & 95 & 57.50 & 37.7 \\
\hline 6 & 65 & 0 & 65 & 100 \\
\hline 7 & 165.50 & 161.64 & 3.86 & 2.3 \\
\hline 8 & 424.50 & 212.25 & 212.25 & 50 \\
\hline 9 & 110 & 42.50 & 67.50 & 61.4 \\
\hline 10 & 50 & 25 & 25 & 50 \\
\hline II & 42.50 & 0 & 42.50 & 100 \\
\hline 12 & 57.14 & 0 & 57.14 & 100 \\
\hline 13 & 185 & 12.50 & 172.50 & 93.2 \\
\hline 14 & 215 & 75 & 140 & 65.1 \\
\hline 15 & 161 & 80.50 & 80.50 & 50 \\
\hline 16 & 60 & 30 & 30 & 50 \\
\hline 17 & 150 & 10 & 140 & 93.3 \\
\hline 18 & 69.50 & 65.64 & 3.86 & 5.6 \\
\hline 19 & 232.50 & 190 & 42.5 & 18.3 \\
\hline 20 & 188 & 160 & 28 & 14.9 \\
\hline 21 & 80.50 & 53.93 & 26.57 & 33 \\
\hline 22 & 85 & 75 & 10 & 11.8 \\
\hline 23 & 85 & 12.14 & 72.86 & 85.7 \\
\hline 24 & 34 & 14.07 & 19.93 & 58.6 \\
\hline 25 & 11.43 & 0 & 11.43 & 100 \\
\hline 26 & 181.50 & 102.50 & 79 & 43.5 \\
\hline 27 & 40 & 20 & 20 & 50 \\
\hline 28 & 70 & 45 & 25 & 35.7 \\
\hline 29 & 171 & 80.50 & 90.50 & 52.9 \\
\hline 30 & 85 & 42.50 & 42.50 & 50 \\
\hline 31 & 25 & 0 & 25 & 100 \\
\hline 32 & 185 & 115 & 70 & 37.8 \\
\hline 33 & 77 & 25.50 & 51.50 & 66.9 \\
\hline 34 & 3.57 & 1.79 & 1.78 & 49.9 \\
\hline 35 & 94.50 & 17 & 77.50 & 82 \\
\hline 36 & 82.50 & 78.64 & 3.86 & 4.7 \\
\hline 37 & 32.50 & 18.57 & 13.93 & 42.9 \\
\hline 38 & 21.25 & 6.07 & 15.18 & 71.4 \\
\hline 39 & 275 & 80 & 195 & 70.9 \\
\hline
\end{tabular}

Notes: Cost 1 refers to the cost of drugs before back titration. Cost 2 refers to the cost of drugs after back titration; the lowest cost still kept blood pressure under control.

Abbreviations: N, Nigerian Naira; S. No., serial number. 


\section{Discussion}

Cost of treatment of hypertension is very high world wide. This observation has been documented in Nigeria. ${ }^{7,8}$ Overall, cost saving without loss of control is desirable and has prompted trial of single pill combination. ${ }^{9}$ The economic burden of hypertension has been put at US\$3.7 trillion in low- and middle-income countries ${ }^{10}$ that include Nigeria. Cost has been shown to hinder compliance especially if treatment is out-of-pocket. When that is the situation, greater cost is brought about when hospitalizations and complication of the untreated condition are considered.

When patients get their drugs at reduced cost, rates of compliance are known to rise. ${ }^{11}$ Dose reduction or drug discontinuation has been considered when need for cost reduction and avoidance of inappropriate adverse events arise. ${ }^{12}$

In this small study where back titration was shown to be effective in hypertensives consistently controlled over 12 months, the cost benefit turned up to be considerable. In a population where the minimum wage is N18,000 monthly, the cost relief by this approach is great and will improve adherence. It will also cut down on consequences of poor control and complication with attendant cost implication. The higher the bill burden the less compliant patients become. ${ }^{13}$

\section{Conclusion}

With the evident benefit of back titration in terms of cost relief and psychology of lower pill burden, it would not be out of place to recommend it routinely in the management of hypertensives especially under expert care. The point must be made that at the moment, this process should be considered off-label. Clinicians are therefore called upon to give it a wider approach. It holds a promise for reduction in side effects of treatment and morbi-mortality consequences of hypertension which have been put at $69.6 \%$ of cardiovascular system admission in a series from Enugu Nigeria, ${ }^{14}$ and a leading cause of cardiovascular disease mortality ${ }^{15}$ world wide. As posited by Elliot, ${ }^{16}$ pharmacoeconomic analysis of factors that impact on health care expenses (antihypertensive therapy and their costs) are considered germane for optimizing current strategies for management of hypertension. This is because hypertension accounts for a greater proportion of health care spending. ${ }^{17}$ This paper has a limitation in its small numbers and the fact that it is a single-center study. The need for replication in different settings involving larger numbers is called for, given the inherent economic benefit of this approach to management especially in resource constrained environments.

\section{Acknowledgment}

The publication fee for this manuscript was kindly covered by the African Centre of Excellence in Phytomedicine, University of Jos, Nigeria.

\section{Disclosure}

The authors report no conflicts of interest in this work.

\section{References}

1. Fischer MA, Stedman MR, Lii J, et al. Primary medication non adherence: analysis of 195,930 electronic prescription. J Gen Intern Med. 2010;25(4):284-290.

2. Honiberg R, Gorden M, Wisniewski AC. Supporting Patient Medication Adherence: Ensuring Co-ordination, Quality and Outcome. URAC; 2011. Available from: http://adhereforhealth.org/upcontent/uploads/ pdf/URAC-MedAdherence_WP.pdf. Accessed December 13, 2016.

3. Osterberg L, Blasclike T. Adherence to medication. N Engl J Med. 2005 ; 353(5):487-489.

4. Ohene Buabeng K, Matowe L, Plange-Rhule J. Unaffordable drug prices: the major cause of non-compliance with hypertension medications in Ghana. J Pharm Pharmaceut Sci. 2004;7(3):350-352.

5. Okeahialam BN. Twelve month follow-up audit of Nigerian hypertensives on back-titration. J Hypertens. 2015;4:1

6. Ambrosioni E. Pharmacoeconomic challenges in disease management of hypertension. J Hypertens Suppl. 2001;19(3):S33-S40.

7. IIesanmi OS, Ige OK, Adebiyi AO. The managed hypertensive: the costs of blood pressure control in a Nigerian town. Pan Afr Med J. 2012;12:96.

8. Ganiyum KA, Suleiman IA. Economic burden of drug therapy in hypertensive management in a private teaching hospital in Nigeria. $\mathrm{Br}$ J Pharm Res. 2014;4(1):70-78.

9. Conen D. Antihypertensive treatment - navigating between cost, compliance and complication. Swiss Med Wkly. 2013;143:w13857.

10. Mutowo MP, Lorgelly PK, Laxy M, Renzaho AMN, Manguiro JC, Owen AJ. The hospitalization costs of diabetes and hypertension complications in Zimbabwe: Estimates and correlations. J Diab Res. 2016;2016:9.

11. Choudhry NK, Avorn J, Glynn RJ, et al. Full coverage of preventive medications after myocardial infarction. NEng J Med. 2011;365:2088-2097.

12. Padwal R, McAlister FA, Wood PW, et al. Telemonitoring and Protocolised case management for hypertensive community dwelling seniors with diabetes: protocol of the TECONOMED randomized control trial. JMIR Res Protoc. 2016;5(2):e107.

13. Thorn S, Poulter N, Field J, et al; UMPIRE Collaborative Group. Effects of a fixed dose combination strategy on adherence and risk factors in patients with or at high risk of cardiovascular diseases: the UMPIRE randomized clinical trial. JAMA. 2013;310(9):918-929.

14. Ike SO. Prevalence of hypertension and its complications among medical admissions at the University of Nigeria Teaching Hospital, Enugu (Study 2). Niger J Med. 2009;18(1):68-72.

15. Chockalingam A, Campbell NR, Folder JG. World wide epidemic of hypertension. Can J Cardiol. 2006;22(7):553-555.

16. Elliot WJ. The economic impact of hypertensive. J Clin Hypertens (Greenwich). 2003;5(3 Suppl 2):3-13.

17. Weaver CG, Clement FM, Campbell NR, et al; Alberta Kidney Disease Network and the Interdisciplinary Chronic Disease Collaboration. Health care costs attributable to hypertension. Canadian population based cohort study. Hypertension. 2015;66(3):502-508. 


\section{Publish your work in this journal}

ClinicoEconomics and Outcomes Research is an international, peerreviewed open-access journal focusing on health technology assessment, pharmacoeconomics and outcomes research in the areas of diagnosis, medical devices, and clinical, surgical and pharmacological intervention. The economic impact of health policy and health systems

organization also constitute important areas of coverage. The manuscript management system is completely online and includes a very quick and fair peer-review system, which is all easy to use. Visit http://www.dovepress.com/testimonials.php to read real quotes from published authors.

Submit your manuscript here: https://www.dovepress.com/clinicoeconomics-and-outcomes-research-journal 